\title{
Intelligent Systems in Manufacturing: Current Developments and Future Prospects
}

\author{
Farid Meziane, Sunil Vadera, Khiary Kobbacy and Nathan Proudlove
}

\begin{abstract}
Global competition and rapidly changing customer requirements are demanding increasing changes in manufacturing environments. Enterprises are required to constantly redesign their products and continuously reconfigure their manufacturing systems. Traditional approaches to manufacturing systems do not fully satisfy this new situation. Many authors have proposed that artificial intelligence will bring the flexibility and efficiency needed by manufacturing systems. This paper is a review of artificial intelligence techniques used in manufacturing systems. The paper first defines the components of a simplified intelligent manufacturing systems (IMS), the different Artificial Intelligence (AI) techniques to be considered and then shows how these AI techniques are used for the components of IMS.
\end{abstract}

Keywords: Intelligent Manufacturing Systems, Artificial Intelligence, Neural Networks, Genetic Algorithms, Knowledge-based Systems, Case-based Reasoning.

\section{INTRODUCTION}

The growing complexity of industrial manufacturing and the need for higher efficiency, greater flexibility, better product quality and lower cost have changed the face of manufacturing practice (Rao et al., 1993). Since the early 50 s when classical control theory was being established, engineers have devised several procedures which analyse or design systems. These procedures can be summarised as (Jamshidi, 1997):

(1) Modelling procedures which consist of differential equations, input-output transfer functions and state-space formulations

(2) Behavioural procedures of systems such as controllability, observability and stability tests.

(3) Control procedures such as series compensation, pole placement, optimal control, robust control etc.

In today's complex systems, the application of these procedures alone may not be sufficient to maximise the performance of a manufacturing organisation. Rodd (1992) also stated that when examining the nature of the different manufacturing process, one is faced with many issues which no single unifying mathematically-provable theory can cope with. Rodd stated the following problems: (1) Inherent instability of the process; (2) Mixture of continuous and batch operations; (3) Incomplete and/or excessive data; (4) Unidentified processes; (5) changed processes and (6) Temporal problems.

In addition to these technical issues, modern manufacturing technology is interdisciplinary in nature and allows the application of different knowledge from other scientific fields such as manufacturing, computer science, management, marketing and control systems. Manufacturing has also shifted from mass production, to a more controlled one where products are only produced if there is a market for them, and when there is a market, they must 
be manufactured quickly, e.g. JIT manufacturing. We need also to look at all aspects of the process before manufacturing a product. We have to make sure that we can do it right, efficiently and cost effectively if we want to make any profit. Therefore our control on the manufacturing process should not be only on machines but should also include human aspects. Another shift of modern manufacturing is from a localised level to total plant-wide control. We need also to predict how our system will perform under certain circumstances. In short, we need to be in a position to model our production and control processes as accurately as possible (Rodd, 1992).

This paper is a review of the use of AI techniques in manufacturing. Indeed, many authors have supported the view that AI can make a significant contribution to improving control and manufacturing systems. The remainder of the paper is organised as follows: in the next section, we present a case for supporting the view that AI can lead to improving manufacturing systems. In section three we outline the AI techniques that are considered in this paper together with the components of a simplified intelligent manufacturing system. Section 4 will look at the different AI techniques used for the different components of an intelligent manufacturing system. The paper concludes with a section on the future trends in using AI for manufacturing systems.

\section{A CASE FOR ARTIFICIAL INTELLIGENCE}

Since its emergence in the $50 \mathrm{~s}$, AI has provided several techniques with applications in manufacturing. In the early years, knowledge based systems attracted many attention. Recently neural networks, case-based reasoning, genetic algorithms and fuzzy logic have attracted more attention and have been successfully employed in manufacturing.

Karwowski and Evans (1986) identified three key reasons why fuzzy logic is relevant to production management, this can be generalised to all AI techniques:

(1) Imprecision and vagueness are inherent to the decision maker's mental model

(2) In the production management environment, the information required to formulate a model's objective, decision variables, constraints and parameters may be vague or not precisely measurable.

(3) Imprecision and vagueness as a result of personal bias and subjective opinion may further dampen the quality and quantity of available information.

The application of AI in manufacturing has been the subject of extensive research in the last two decades. This surge in the application of $\mathrm{AI}$ in manufacturing is mainly due to the availability of powerful computers. In this paper, we concentrate on the work done since 1995 and report mainly on the journals where most of the research has been published. Table 1 summarises the journals and the number of articles published on the use of AI techniques in manufacturing systems per year and per journal. Other journals that contain papers on the use of artificial intelligence in manufacturing, and have been consulted, include Robotics and Integrated Manufacturing, IEEE Transactions on Robotics and Automation, Integrated Manufacturing Systems and Computers, Computers and Industrial Engineering and Operations Research. This review focuses on the use of the following AI techniques: expert systems, neural networks, genetic algorithms, fuzzy logic, case-based reasoning and any combination of these techniques. There have been a number of more specialised surveys than the one presented in this paper which is a very general survey. A summary of these reviews include: 
- Fuzzy set theory applications in production management research. (Karwowski and Evans,1986 and Guiffrida and Nagi, 1998)

- Application of Fuzzy set Theory (Maiers and Sherif, 1985).

- Use of genetic algorithms in integrated planning and scheduling (Morad and Zalzala, 1999).

- Use of expert systems in quality control (Kuo and Mital, 1993).

- Expert systems in computer aided process planning (Alting and Zhang, 1989 and Kiritsis, 1995).

- Applications of neural networks in chemical process control (Azlan, 1999).

- Use of genetic algorithms for the facility layout problem (Mauridou and Pardalos, 1997)

- Intelligent management systems in operations (Prodlove et al., 1997).

- Application of Neural Networks in Manufacturing (Zhang and Huang, 1995)

Reviews on manufacturing include:

- Intelligent Manufacturing (Kopacek, 1999).

- Design and Planning problems in flexible manufacturing systems (Kouvelis, 1992)

- Intelligent real-time flexible manufacturing systems (FMS) control (Shukla and Chen, 1996).

Table1: Number of published papers on the use of AI in manufacturing in selected journals (1995-1999)

\begin{tabular}{|l|l|l|l|l|l|l|}
\hline Journal & $\mathbf{1 9 9 5}$ & $\mathbf{1 9 9 6}$ & $\mathbf{1 9 9 7}$ & $\mathbf{1 9 9 8}$ & $\mathbf{1 9 9 9}$ & Total \\
\hline International Journal of Production Research & 17 & 12 & 16 & 21 & 22 & $\mathbf{8 8}$ \\
\hline Computers in Industry & 3 & 12 & 15 & 12 & 5 & $\mathbf{4 7}$ \\
\hline Artificial Intelligence in Engineering & $*$ & 12 & 13 & 8 & 25 & $\mathbf{5 8}$ \\
\hline The Internat. Journal of Advanced Manufacturing Technology & 9 & 15 & $*$ & 15 & 13 & $\mathbf{5 2}$ \\
\hline Journal of Intelligent Manufacturing & 9 & 16 & 13 & 19 & 10 & $\mathbf{6 7}$ \\
\hline Engineering Applications of Artificial Intelligence & 26 & 27 & 22 & 35 & 27 & $\mathbf{1 3 7}$ \\
\hline IEEE Transactions on Systems, Man and Cybernetics & 16 & 24 & 23 & 27 & 24 & $\mathbf{1 1 4}$ \\
\hline Total & $\mathbf{8 0}$ & $\mathbf{1 1 8}$ & $\mathbf{1 0 2}$ & $\mathbf{1 3 7}$ & $\mathbf{1 2 6}$ & $\mathbf{5 6 3}$ \\
\hline
\end{tabular}

\section{AI TECHNIQUES AND COMPONENTS OF AN INTELLIGENT MANUFACTURING SYSTEMS}

This section contains a very brief and much simplified outline of the main AI techniques and the components of a simplified model of an intelligent manufacturing system.

\section{AI Techniques}

\section{Knowledge based systems}

The first attempt to be widely used to equip manufacturing systems with some degree of intelligence was the use of Knowledge Based Systems (KBS) (Schreiber et al., 1993). They seek to incorporate human knowledge about an application area, usually elicited from experts in the particular domain, so that the system can automatically replicate 
aspects of best practice. The human knowledge is represented using the IF-THEN production systems or more structured formats such as frames and semantic nets (Vadera, 1989).

\section{Neural networks}

Neural networks (Gurney, 1997 and Mehrotra et al. 1997) are based on ideas about how the brain may work. Input stimuli (e.g. the parameter values encountered in a problem situation) are connected through a network of nodes to output nodes (e.g. the solution). This technique has been widely used in many classification and optimisation situations. History data are used to 'train' the network, automatically determining the most appropriate configuration of the hidden network.

Fuzzy logic

Fuzzy logic allows the representation and processing of uncertain or vague information such as linguistic statements, for example the customer desires a car which is "fairly luxurious". Judging the degree of membership of classes (e.g. "luxury" and "economy") way of quantifying information that otherwise could not be used in mathematical modelling or target setting: The reader is refereed to Klir and Yuan (1995) for a good tutorial.

\section{Genetic algorithms}

Genetic Algorithms (Goldberg, 1989 and Nissen and Biethahn, 1995) use ideas from population genetics for solving complex global optimisation problems. A pool of potential candidate solutions evolve through reproduction and mutation of the fittest and elimination of the least promising solutions of each generation are made 'extinct'.

\section{Case-based reasoning}

In Case-Based Reasoning (CBR), the intelligent component of the system contains a history of past problems and the (successful) solutions applied. Future problems can then be considered through analogy with these past cases to rapidly home in on the most promising type of solutions. A further step is incorporating machine learning through the updating of the 'case-base' with those for which the solutions suggested proved successful (Watson and Marir, 1994, Kolodner, 1993).

\section{Components of an intelligent manufacturing system}

As mentioned in the previous section, the manufacturing process is a complex one and can be decomposed into several components. Rao et al. (1993) decomposed intelligent manufacturing systems into the following components: intelligent design, intelligent operation, intelligent control, intelligent planning and intelligent maintenance. We modify this decomposition slightly to reflect the current trends in the literature on intelligent manufacturing systems as shown in figure 1. We give a brief description of each phase in this section, and in the following section, we look at how AI techniques are used within each component. 


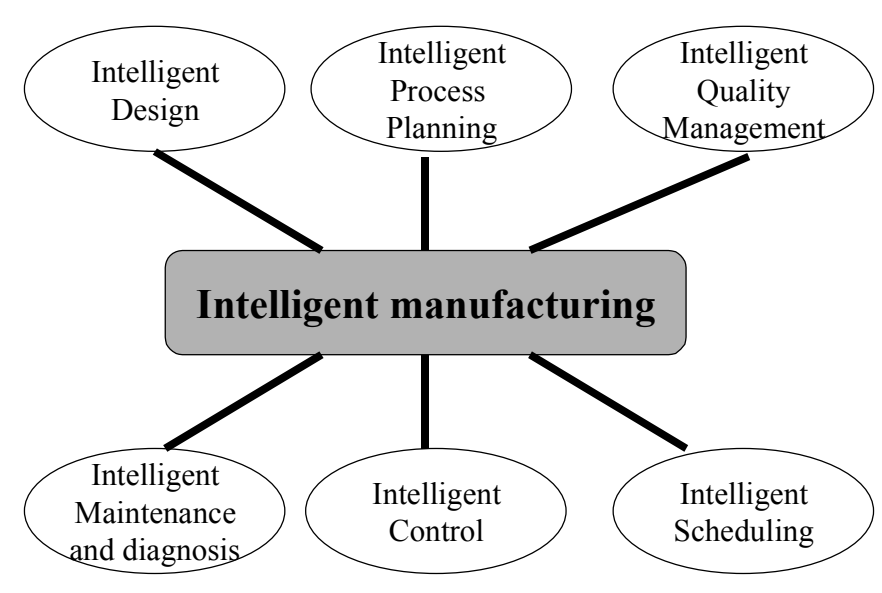

Figure 1: Components of an intelligent manufacturing systems (adapted from (Rao, 1993))

\section{Intelligent design}

The importance of product design is undeniable. A firm's products or services are typically the primary source and focus of contact with its customers, and the development of new designs plays a key role in establishing and maintaining a competitive position for most firms. There are many problems in design manufacturing systems. A review of the problems encountered in manufacturing systems can be found in (Kouvelis, 1992). In this paper, process design is also included in intelligent design.

\section{Intelligent process planning}

Intelligent process planning is a dynamic and complex activity. Process planning provides a detailed description of manufacturing capabilities and requirements for transforming a stock of raw material into a completed product (Requicha and Vandenbrande, 1988). Intelligent process planning include Computer-Aided Process Planning (CAPP) and facility and location layout. Process planning is the interface between Computer-Aided Design (CAD) and Computer-Aided Manufacturing (CAM). CAPP is vital to achieving the ultimate goal of complete integrated factories of the future. A CAPP system contains a large amount of knowledge that includes rules about arranging machine operations and facts about the machine shop. Inventory management is also considered under this section because successful inventory management is essential for successful manufacturing and requires sophisticated methods to cope with the continuously changing environment. Literature is rich with papers about theoretical independent demand inventory modelling but practice lags behind these developments. AI can play an important role in aiding practitioners to implement such models and also to overcome the problems associated with managing largescale inventories

\section{Intelligent quality management}

Quality management has evolved from a focus on inspection through quality control techniques such as statistical process control (SPC) and through quality assurance to current total quality management (TQM) (Proudlove et al., 1997). More organisations are involving customers in the early stages of design to assure quality and a market for 
their products. Zhang and Huang (1995) stated that there are two approaches to quality assurance: reactive quality assurance and proactive quality assurance. Reactive tools include sampling plans, lot acceptance determination, scrap or rework analysis etc. Proactive strategy requires an emphasis on physical cause-effect knowledge, risk analysis, experience and judgement.

\section{Intelligent maintenance and diagnosis}

The goal of fault diagnosis is to detect the faults and their causes early enough, so that failure of the overall system can be avoided. From the fault-detection point, faults are divided into three categories, actuator faults, component faults, and sensor faults. The basic task of fault diagnosis is to detect the faults that occur, and to provide information about their size and source (Frank and Koppen-Seliger, 1997). Three steps need to be taken in fault diagnosis: signal generation, fault classification and evaluation, and fault analysis. See (Frank and Koppen-Seliger, 1997) for a survey on the use of AI techniques in fault diagnosis.

Maintenance management and planning is a fundamental component of successful manufacturing operations. Scheduling preventive maintenance activities is an important aspect of maintenance management and it is particularly challenging for large and complex systems with many thousands of components. There are some useful commercial software packages for optimising maintenance activities available in the market (Dekker, 1996). However, most of these software packages have restrictive applicability since they are usually developed for very specific tasks. Dhaliwal (1986) and Kobaccy (1992) suggested the development of an approach for maintenance decision support that combines optimisation models and artificial intelligence techniques. Since then several attempts have been made to develop such systems.

\section{Intelligent scheduling}

Scheduling is a resource allocation problem subject to allocation and sequencing constraints. It is an optimisation problem. The objective in optimisation is to allocate a limited amount of resources to a set of tasks such that cost functions are optimised.

\section{Intelligent control}

The basic objective of control is to provide the appropriate input signal to a given physical process to yield the desired response. It is a complex process that continues to require human intelligence to ensure proper operation.

\section{INTELLIGENT DESIGN}

This section reviews the use of AI techniques in intelligent design.

\section{Knowledge based systems}

Knowledge based systems were extensively used in early intelligent manufacturing systems and many of them were used in the design phase. Chon et al., 1993, reported the use of a knowledge based system for centrifugal fan blade design. Significant factors such as input variables, output variables and constraints are conceptualised. The knowledge base is developed using the expertise of a fan design expert and a corresponding rule set that combines the centrifugal fan theory. The experience of human experts is developed and applied using an inference engine. A 
number of KBS were used in the electronic engineering field. A survey of the applications developed before 1993 can be found in (Rowland and Jain, 1993). In the same period, KBS were also used for the design of circulating fluidised bed boiler's (Mitra et al., 1993) and for designing computer network topologies (Pierre, 1993).

Basu et al. (1995) used an expert system for the design of manufacturing cells. The starting point for the expert system is the initial solution generated by traditional mathematical techniques. Based on a flexible set of user-driven quantitative and qualitative factors, the expert system evaluates these preliminary solutions for feasibility and quality. If the solutions are not satisfactory, the system suggests modifications. The trend of using KBS for manufacturing design has continued throughout the 90's. Recently, KBS were used for concurrent engineering in metallurgy component design, materials selection, powder packing and compaction (Smith and Midha, 1999).

\section{Neural networks}

The product design process can be modelled as a mapping from a function space to a structure space to a physical space (Kumara and Kamarthi, 1991). An experienced human designer is usually aware of the structures that satisfy a particular set of functions. In his/her memory the designer may have stored the representations of a number of design solutions. By association, the designer can selectively retrieve those designs. Neural networks are very well suited for modelling the human associative memory (Zhang and Huang, 1995) and this has attracted a lot of research on the application of NNs for product design.

Gunasekera et al. (1998) used a neural network model for the flat rolling process. The neural network was based on the backpropagation paradigm. A nonlinear mathematical model based on the slab method was developed to guide and supervise the learning procedures. Neural Networks have been used in the design of cellular manufacturing systems. Rao and $\mathrm{Gu}$, (1995) used a multilayered neural network to configure and alternate cell designs by considering multiple constraints and objectives. Kusiak and Lee (1996) constructed a three layer NN for designing a cellular manufacturing system that integrates several manufacturing functions.

\section{Genetic algorithms}

Bos (1998) used a procedure based on the combination of a genetic and a gradient-guided optimization algorithm for the design of a second-generation supersonic transport aircraft. Karafyllidis (1999) has developed a method for designing a dedicated processor, which executes a cellular automaton algorithm that simulates the photolithography process. Starting from a cellular automaton with a continuous state space which simulates the photolithography process, the genetic algorithm is used to find a cellular automaton with discrete state space, having the smallest possible lattice size and the smallest possible number of discrete states, the results of which are as close as possible to the results of the cellular automaton with continuous state space. The dedicated processor that executes the discrete cellular automaton algorithm was designed to the level of a silicon compiler output.

Scott et al. (1999) provided an approach for multi-parameter controller design. The electromechanical actuators specific to thrust vector control applications are addressed. The control solution involves a traditional PID controller with an additional control filter. Genetic algorithms are utilized to optimize the controller gains using a frequencydomain technique. 


\section{Fuzzy logic}

Optimising the efficiency in cutting a sculptured surface using numerically controlled machining techniques needs to carefully consider the relationship between cutting edges and surface geometry. A fuzzy basis material removal optimisation approach is suggested by Ip (1998) to compensate the variation of cutting speed due to the change of gradient on the sculptured surface in machining process. Fuzzy modeling is used for the Penicillin-G conversion process (Babuska et al., 1999). A linguistic fuzzy model, which represents the kinetic term of the conversion, is developed from experimental data by means of fuzzy clustering

\section{Case based reasoning}

The frequent use of past experience by human engineers when solving new problems has led to an interest in the use of case based reasoning (CBR) to help automate engineering design. Purvis and Pu (1998) developed a constraint based methodology for case combination. The methodology is implemented in a case based reasoning system called COMPOSER and has been tested in two design domains: assembly sequence design and configuration design. Gao et al. (1998) used CBR for mechanical plan systems design. Design plans are stored as the actual cases in the CBR system. CBR is used for the design of bar linkages (Bose et al., 1997), Fixture design (Sun and Chen, 1995).

A product may have different ways of disassembly and experience is important during disassembly if we want to satisfy goals such as part reuse, recycle or discard. Zeid et al. (1997) have proposed a CBR approach to solve design for disassembly (DFD) problem.

\section{Hybrid systems}

Chen et al. (1998) have developed an integrated expert system that consists of a knowledge base, a database, patternrecognition, ANN, and GA modules for complicated chemical reaction systems used to prepare industrial materials. The system has been used in many applications including the production of alloy steel, synthetic rubber, ceramic materials production and materials design of composite materials, high temperature (Tc) superconductors, and ceramic semiconductors.

Lee et al. (1999) have developed a fuzzy non linear programming model to optimise machining operations. It uses fuzzy logic together with traditional mathematical programming to make a more flexible, reliable and acceptable model. In addition, the model can consider the qualitative viewpoint of the decision maker. The model also uses a NN model which can be used to assess the machinability of the machining operations. The output from the fuzzy non-linear programming model provides the input for the NN model.

A material design system has been developed, utilising mathematical modelling and knowledge-based approaches by Shivathaya and Fang (1999). The Knowledge-Based System (KBS) generates about 15-30 different target compositions for steelmaking for each customer order. Fuzzy logic is applied in the system for the design of steel plates, to rank the alternative target compositions for steelmaking according to the degree to which they will satisfy customer's requirements.

\section{INTELLIGENT PROCESS PLANNING}

This section reviews the use of Artificial intelligence during process planning and inventory management. 


\section{Knowledge based systems}

By 1993, a large number of expert system had been developed to assist process planning. An early survey on the use of expert systems in process planning was carried out by Alting and Zhang (1989) while a more recent survey was carried out by Kiritsis (1995). The maturity of the use of expert system in process planning has pushed some researchers to look at the development of tools to build expert system for process planning (Eskicioğlu, 1992).

Wong and Siu (1995) used an expert system for automatic process selection and sequencing. This process selection and sequencing algorithm comprises three sub-algorithms, the transformation algorithm, the refinement algorithm and the linearization algorithm. The module is a part of a prototype expert process planning system for the machining of prismatic parts. Pande and Desai (1995) used an expert system (EXTURN) for the process planning of rotationally symmetric components manufactured on single spindle automats. The ES comprises an interactive graphical feature modeller and process planning modules for operation extraction, sequencing, tool selection, and process plan generation.

\section{Neural networks}

The learning ability of NNs provides a promising approach for automated knowledge acquisition and can be advantageously used in the building of automated process planning systems.

The application of perceptron-type neural networks to tool-state classification during a metal-turning operation is reported by Dimla (1999). The inputs to the networks consist of descriptive, independent and different source process parameters of the cutting process. The cutting conditions were fused with the process parameters, and a single network output defined the tool state.

\section{Genetic algorithms}

Mauridou and Pardolos (1997), have carried out a comprehensive survey on the use of genetic algorithms for facility layout. GAs have been successfully used in layout design (Suresh et al., 1995, Gupta et al., 1996 and Rao et al., 1999), and have been shown to outperform human and KBS designs (Hamamoto, 1999). Parallel GAs were also used to solve the layout problem with geometric constraints (Tam and Chan, 1998). Hamamoto (1999) integrates GAs with an embedded simulation model to tackle the facility layout problem for pharmaceutical factories. The proposed method allows the user to specify objectives for each particular case and generate layouts that achieve those objectives. The experimental results show that the proposed model outperforms all existing computer layout algorithms such as CRAFT, LORELAP and LOCPPLAN.

Bhaskara et al. (1999) demonstrates the application of GAs as a global search technique for a quick identification of optimal or near optimal operation sequences in a dynamic planning environment. The approach uses a precedence graph based on various manufacturing constraints, generates a precedence cost matrix using production rules and applied GAs to arrive at optimal or near optimal sequences.

\section{Fuzzy logic}

Many of the factors affecting facility layout and location problems are difficult to measure precisely and require a considerable amount of human judgement. Closeness measures are a key input in nearly all facility layout models 
and are often determined in the form of a closeness rating. Subjective weights are often used with closeness measures when determining criterion based scores to determine the layout of departments or machines. Fuzzy set theory effectively models facility layout and location by incorporating subjectivity in the parameters used by the models (Guiffrida, 1998). Fuzzy set theory has also been applied in inventory production and process plan selection. Inventory management requires demand forecasts as well as parameters for inventory-related costs such as carrying, replenishement, shortages and backorders (Guiffrida and Nagi, 1998). Precise estimations of these parameters are difficult.

Dweiri and Meier(1996), defined a fuzzy decision-making system (FDMS) consisting of four principle components: (1) fuzzification of input and output variables; (2) the experts' knowledge base; (3) fuzzy decision making and (4) defuzzification of fuzzy output into crisp values. The analytical hierarchy process is used to weight factors affecting closeness ratings between departments.

\section{Case based reasoning}

BenArieh and Chopra (1997) describe a process planning system that utilises case-based reasoning. The system, CBPlan, uses a feature-based part representation as a key to the case library. Champati et al. (1996) also used a CBR approach for the automated sequencing in intelligent process planning.

\section{Hybrid systems}

Malakooti et al. (1995) developed a monitoring and supervising system for machining operations using in-process regression for monitoring and adaptive feedforward artificial neural networks for supervising. The monitoring system predicts tool life by using different sensors for gathering information based on a regression model that allows for the variations between tools and different machine setups. The regression model makes its prediction by using the history of other tools and combining it with the information obtained about the tool under consideration. The supervision system identifies the best parameters for the machine setup problem within the framework of multiple criteria decision making. Ming (1999) has combined expert systems and NNs to develop a CAPP system.

Kobbacy and Liang (1999) presented a serious attempt at developing intelligent inventory management system. The system has an appropriate knowledge scope and focuses on the interrogation of the historical data rather than on asking the user to describe the system under analysis. The system first identifies a demand pattern based on the analysis of history data then it uses its model selection rule base to select an appropriate model from the model base. Other attempts have been made to use AI in managing dependent demand inventories. Notably several applications have been published in the area of Just in Time (JIT) including the work of Fielder et al (1993 ), Rixen et al(1995) and Ettl and Schwehm (1995). A wider discussion can be found in the review of Proudlove et al (1998)

\section{INTELLIGENT QUALITY MANAGEMENT}

This section reviews the use of AI techniques in manufacturing quality management.

\section{Knowledge based systems}


Statistical quality control (SQC) is one of the most effective tools for ensuring quality products and services by means of control charts. The interpretation of chart patterns, trends and associated diagnosis require expert knowledge. Quality control expert systems are used to help solve these problems and also to provide non specialised staff involved in quality with expert knowledge. A good review of expert systems used in quality control up to 1992 can be found in (Kuo and Mital, 1993). Deslandres and Pierreval (1995) developed SYSMIQ, a knowledge-based advisory system for quality control to assist decision-makers in selecting the best quality tools and techniques and correctly apply them on the shop floor.

\section{Neural networks}

Reactive quality assurance is strongly related to monitoring and diagnosis. Therefore NNs can play an important role, especially where high processing and classification capabilities are required (Zhang et al., 1996). NN techniques can also be used in proactive quality assurance.

NNs have been used for fault diagnosis in hydraulic forging presses (Lin et al., 1995b). The technical descriptions of the presses and the 47 major possible faults are presented. For diagnosing these faults, a back propagation NN was utilised and provided 99\% accuracy in identifying causes of the failures of hydraulic forging presses. Chinnan and Kolarik (1997) proposed the use of NNs for optimising the controllable variables of a process to achieve real-time quality control.

\section{Genetic algorithms}

There is little work reported on the use of fuzzy logic for quality. Gill and Bector (1997) used a fuzzy linguistic approach to quantify part feature information for the part family formation problem.

\section{Fuzzy logic}

In early research, Fuzzy Logic (FL) was mainly used in acceptance sampling and statistical process control (Chakraborty, 1992\&1994, Kanagawa and Ohta, 1990 and Kanagawa et al., 1994, Wang and Chen, 1995). In more recent research, fuzzy logic is used in quality topics such as quality improvement and quality function deployment (QFD) (Gutierez and Carmona, 1995, Khoo and Ho, 1996, Yongting, 1996, Wang, 1999 and Chan et al., 1999).

Wang and Chen (1995) presented a fuzzy mathematical programming model and solution heuristic for the economic design of statistical control charts. After noting that quality decisions are inherently ambiguous, Gutierrez and Carmona (1995) proposed a fuzzy multicriteria decision theory framework for modelling quality decisions. The framework was demonstrated on an automobile manufacturing example consisting of the following five decision alternatives: purchasing new machinery, workforce training, preventive maintenance, supplier quality and inspection. Khoo and Ho (1996) presented a framework for a fuzzy quality function deployment (QFD) system in which the customer requirements can be expressed as both linguistic and crisp variables. The QFD system was demonstrated for determining the design requirement of a flexible manufacturing system Yongting (1996) stated that a fundamental shortcoming of traditional quality management is its failure to deal with quality as a fuzzy concept. Ambiguity in customer's understanding of standards, the need for multi-criteria appraisal and the psychological aspects of quality 
in the mind of the customers are examples of parameters that support the use of fuzzy logic to model quality. QFD consists of many phases and the first one translates customer needs for a product into technical measures. Chan et al., (1999) proposed a fuzzy and entropy method to obtain the final importance rating of the customer needs. The ratings form the basis for the company to make the product more attractive to customers and thus more competitive. The fuzzy method is used to convert the customers' importance assessments of the needs to fuzzy members and the relative importance ratings of the customer needs are then obtained using fuzzy arithmetic. The paper concludes that the proposed approach shows clearly the consistency of QFD with multiple criteria decision making (MCDM) in determining the relative importance ratings of customer needs. Fuzzy logic is also used by Fung et al. (1999) to analyse customer requirements.

Wang (1999) considers QFD planning as a multi-criteria decision problem and proposes a fuzzy outranking decision model to prioritise design requirements recognised in QFD. The inputs of QFD are represented with the linguistic terms of fuzzy sets, which are appropriate for characterising imprecise and uncertain product information. Fuzzy outranking relations based on the possibility theory is used to model the imprecise preference relations found in design requirements. The purpose of the model is to achieve customer satisfaction and a balanced design of the product.

\section{Case based reasoning}

Malek et al. (1998) developed an operator support system to help and guide the operator in decision making during the control of the plastic injection moulding process. The main objective was to increase the quality during production. The approach used a CBR and learning system.

\section{INTELLIGENT MAINTENANCE AND DIAGNOSIS}

The use of Ai techniques in maintenance and diagnosis is reviewed in this section.

\section{Knowledge based systems}

It has been reported that analytical approaches are not adequate for fault diagnosis (Frank, 1997), this is particularly due to the fact that the knowledge to be processed is commonly incomplete and therefore cannot be represented by analytical models. Fault classification and evaluation is a complex logical process that requires intelligent decision making techniques. Therefore, knowledge based methods are of great importance in fault diagnosis and expert systems have so far been applied successfully for fault diagnosis (Frank, 1997). A number of KBS were used for maintenance and fault diagnosis. A survey on the use of KBS for failure diagnosis before 1993 can be found in (Rowland, 1993). Arslan et al.. (1993) reported the use of an expert system for failure diagnosis for printed circuit boards. The KBS exploits functional test data, which is output from automatic test equipment which is used to test every board subsequent to manufacture. Fujikawa and Ishii (1995) use a KBS to identify the causes of various manufacturing defects in hot forging and suggest remedies. 
For maintenance, several systems have been developed to tackle specific industrial applications. For example Clark et al (1992) developed a knowledge-based system to optimise the building management maintenance and Batanove et al (1993) developed EXPERT-MM: a KBS for maintenance management for a large manufacturing company. A more general approach based on knowledge-based reasoning was adopted by Kobaccy et al (1995) and Zhang and Jardine(1997). Kobbacy et al (1995) developed IMOS, a prototype intelligent maintenance optimisation system aimed at developing and enhancement of preventive maintenance routines for large and complex industrial systems. IMOS has a rule base for selecting an appropriate model for application based on identification of maintenance data pattern. Zhang and Jardine(1997) proposed a similar smart system for data-analysis models and optimising replacement age.

\section{Neural networks}

The fault identification process is essentially a pattern recognition procedure in which the analysed signals are used to make a decision. NNs, which have learning and self-organising abilities, can be advantageously used in pattern recognition. NNs have been widely used in monitoring and diagnosing (Zhang and Huang, 1995).

Lately, NNs have been suggested as alternatives to state process charts, and shown to exhibit superior performance in detecting non-random patterns (Chang and Ho, 1999). Researchers are working to combine monitoring of process means with monitoring of process variance (e.g. Chang and Ho, 1999, Ho and Chang, 1999, Dedeakayogullari and Buma, 1999). The ability of NNs to detect several patterns occurring simultaneously is also being investigated (Guh and Tannock, 1999).

NNs have been used for matching stereoscopic pictures and correcting 3D measurement error (Tien and Chang, 1999) extending earlier work by Su et al. (1995) and identifying product defects (e.g. Kim and Kumara, 1997; Wang and Huang, 1997). A feed forward NN has been used for manufacturing diagnosis by Ransing and Lewis (1997).

\section{Fuzzy logic}

Fault identification can be seen as a classification problem. The task is to match each pattern of the symptom vector with one of the preassigned classes of faults. The principle of fault evaluation using fuzzy logic consists of a threestep process. First the symptoms have to be fuzzified, then they have to be evaluated by an inference mechanism using fuzzy IF-THEN rules, and finally they have to be defuzzified (Frank, 1997). The fuzzification of the signals is a mapping of the representation using crisp values into a representation by fuzzy sets. With the aid of a fuzzy relation, the set of the fuzzified signals is transformed into a set of fuzzy statements (faults). Finally, the fuzzy information on the faults has to be converted into crisp sets such as yes-no statements. Khoo et al. (1999) propose the use of fuzzy logic techniques rather than NNs, which require long training times and large amounts of data, or KBS, which are domain dependent and have difficulty dealing with novel situations.

\section{Case based reasoning}

Xia and Rao (Xia and Rao, 1999) developed a dynamic CBR system that can represent system dynamics and faultpropagation. The CBR include mechanisms such as tagged indexes, dynamic and composite features, and multiple indexing paths. 


\section{Hybrid Systems}

Analysis of a typical large data file in IMOS (Kobbacy et al 1995) shows that about two thirds of components cannot be modelled. Mostly because of an insufficient number of history records needed for model selection. Some of the cases which could not be modelled may have parameters with values close to those of a model's acceptance level which have been based on arbitrary expert judgement.

Jeon (2000) developed a hybrid intelligent maintenance optimisation system (HIMOS) for decision support which aims at overcoming the problems of IMOS. The key to this analysis is the application of intelligent judgement in selecting the most suitable model from a model-base utilising a hybrid knowledge/case based system (KBS/CBR). Thus initially a rule base is applied to select a model. If no model is matched, the system reverts to its historical casebase to match the current case with a similar case that has been previously modelled. This double reasoning adds to the system's true learning capabilities (intelligence) and increases the rate of success of model selection significantly. Labib et al (1997) used fuzzy logic combined with a rule base to develop an 'Intelligent Maintenance Model' which is applied to a manufacturing company to identify the most critical machines and determine appropriate maintenance action.

\section{INTELLIGENT CONTROL}

This section summarises the use of AI techniques in control.

\section{Neural networks}

Neural networks have several unique characteristics that allow them to perform some of the complex process control tasks that are traditionally reserved to humans (Zhang and Huang, 1995). Neural networks can (Hall and Lu, 1992):

(1) be used to accurately represent response surface models of complex processes,

(2) emulate the abilities of humans to incorporate new knowledge into existing models, providing the capability for self improvement and adaptation,

(3) emulate human abilities to reason from a general model to a specialised case, making human-like assumptions when faced with incomplete data,

(4) emulate human knowledge fusion capabilities by forming a single, coherent process model from a variety of partial knowledge sources.

Hao et al. (1995) used a neural network approach in real-time control of flexible manufacturing systems. A hierarchical manufacturing controller, consisting of two NN structures, was used. The first NN participates in the feasibility analysis, and the other, at the lower level, in the process of dispatching and control.

Sung (1999) has used a multilayer perceptron NN for a batch process in a wafer fabrication. Whenever, a batch processing machine is available, a batching policy can be implemented to make a decision either to process a batch immediately or to wait for additional wafer lots to arrive. Acosta et al. (1999) presented a control algorithm based on NNs. The control algorithm has been applied to a robot arm which has a highly nonlinear structure. The control technique proposed has provided satisfactory results. A decentralised model has been assumed where a controller is associated with each joint and a separate $\mathrm{NN}$ is used to adjust the parameters of each controller. NNs have been used to adjust the parameters of the controllers. 


\section{Genetic algorithms}

Lenon (1999) discusses a variety of genetic adaptive control methods, and gives an extensive comparative analysis of their performance relative to conventional adaptive control techniques. Ong and Khoo (1999) used a GA for optimising the sequence of component placements onto a printed circuit board and the arrangement of component types onto feeders simultaneously.

\section{Fuzzy logic}

Caprihan et al. (1997) used a fuzzy system for the control of flexible machines operating under information delays The system comprises a flexible machine capable of processing two different part types and operating under an online control system.

\section{Hybrid systems}

Suresh et al. (1999) proposed a pattern recognition approach based on a fuzzy ART neural network for rapid scanning of families of parts having a similar sequence of operations. First a representation schema for operation sequencing was developed and the fuzzy ART NN was modified to suit this application.

Filipic et al. (1999) combined machine learning and evolutionary optimisation in learning to control a physical device. The knowledge is first made explicit by means of machine learning, and then a genetic algorithm is used to improve the control performance with respect to chosen criteria. This hybrid control-synthesis scheme was tested in swing control on a model of a container crane. It has proved successful in reducing the number of trials needed for optimisation, which is especially important when dealing with physical devices. Vishnupade (1996) used NNs and fuzzy logic for the control of manufacturing systems. The underlying nonlinear process is modelled by artificial NNs and process control is performed by fuzzy logic. Fuzzy rules are automatically generated from the trained NN.

Ortega et al. (1998) propose the use of a fuzzy logic and GAs to develop a control system for provision of spacecraft servicing to a space station which comprises the tasks of assembly, resupply, repair and maintenance of manufactured space parts in-orbit. The geno-fuzzy controller is a knowledge-based controller that performs the closed-loop operations autonomously. It produces smooth control actions in the proximity of the target and during the docking, to avoid disturbance torques in the final assembly orbit. A GA is used to optimise the controller so as to reduce docking time and fuel consumption.

\section{INTELLIGENT SCHEDULING}

\section{Neural networks}

NNs which can achieve high computation rates by employing a massive number of simple processing elements with a high degree of connectivity among the elements, provide a new approach for optimisation problems. More specifically, feedback networks provide a computing model capable of exploiting fine-grained parallelism to solve a 
rich class of optimisation problems (Zhang and Huang, 1995). NNs have been successfully applied to the solution of constrained optimisation problems. The scheduling problem can be solved using NNs to reduce the computational complexity. It is argued by Grabot (1998) that providing a feasible schedule is not sufficient anymore. Human expertise becomes necessary in order to improve the provided solution. This improvement requires the definition of synthetic performance indicators allowing the assessment of a schedule before choosing improvement actions. A hierarchical structure of performance indicators is suggested to aggregate the degree of satisfaction of elementary objectives, thus allowing the definition of a compromise between these elementary objectives. NNs have been tested in order to emulate the expertise involved in the definition of such compromise.

\section{Genetic algorithms}

Candido (1998) used a GA to solve job scheduling problems with many constraints such as jobs with several subassembly levels, alternative processing plans for parts and alternative resources for operations, requirements of multiple resources to process an operation, resource calendar, batch overlap and sequence dependent setups. The system uses modified schedule generation algorithms to obtain a set of initial solutions. Each initial solution is enhanced by a local improvement procedure. Then a hybrid genetic algorithm which incorporates a local hill climbing procedure is applied to the set of local optimum schedules. Webster (1998) used a GA for scheduling jobs about an unrestricted common due date on a single machine. The objective is to minimise total earliness and tardiness cost where early and tardy penalty rates are allowed to be arbitrary for each job.

Lam et al. (1999) used GAs for a scheduling problem encountered in a semi-conductor manufacturing company where the time for designing products needs to be minimised. The paper supports the view that GAs can provide near optimal solutions to problem instances that are too large to model otherwise but are nevertheless present in a wide variety of industrial scenarios. Min and Cheng (1999) have used GAs for the identical parallel machine scheduling problem for minimising the makespan.

\section{Fuzzy logic}

Fuzzy techniques have been suggested to adapt the preference levels of the multiple objectives present in many scheduling problems, in response to dynamic changes in the environment such as unexpected rush orders and unavailable resources (Yu et al., 1999).

Shipley (1996) incorporates fuzzy logic, belief functions, extension principles and fuzzy probability distributions to develop a fuzzy PERT algorithm. The algorithm is applied to a real-world project consisting of eight activities involved in the selling and producing of thirty television commercials. Yu et al. (1999) proposed an approach to FMS scheduling with multicriteria based on fuzzy inference. The proposed system has the following characteristics: (1) each criteria or objective has a preference level at the scheduling time; (2) all objectives and their preference levels are considered in the decision time; (3) the changes in the conditions of the factory are captured in real time by a fuzzy inference model that maps the changes to the proper preference levels; (4) multi-criteria scheduling is realised using a partition method based on the preference levels obtained from fuzzy inference. The proposed system performed very robustly with respect to shop workload for all used performance measures. 


\section{Case based reasoning}

Using CBR in scheduling involves the definition of a scheduling problem, then search and retrieval of a case similar to it and finally building a new schedule. Cunningham and Smyth (1997) explored the components of a scheduling system using CBR. The authors started first by providing a solution to the travelling salesman problem and then to a single machine scheduling problem with sequence dependent setup times. Coello and DosSantos (1999) used CBR and heuristic search for a real-time scheduling system. The problem addressed involves scheduling sets of tasks with precedence, ready time and deadline constraints.

\section{Hybrid systems}

Szelke and Markus (1997) combined machine learning techniques and CBR to solve the shop floor scheduling problems. Kim et al. (1998) used an integrated approach of inductive learning and competitive NNs for developing multi-objective FMS schedulers. The FMS scheduler can assist the operator to make a decision in real time, while satisfying multiple objectives desired by the operator. Lee et al. (1998) combined GAs and machine learning to develop a job shop scheduling system. The idea was to generate empirical results using machine learning for releasing jobs into the shop floor and a genetic algorithm to dispatch jobs at each machine.

\section{FUTURE}

Table 2 summarises the published papers referred to in this paper classified by manufacturing processes and AI techniques used. This table shows that there are some areas that are well researched such as the use of fuzzy logic in maintenance, neural networks in diagnosis and genetic algorithms in process planning. However, there are many areas where more research is needed. There is little work reported on the use of neural networks in process planning, fuzzy logic in process planning, maintenance and diagnosis, control and scheduling. There is also little work on the use of genetic algorithms in design and quality. There is nearly no attempt in using CBR in quality, maintenance and control. These are the areas we believe artificial intelligence should concentrate in the future to further improve manufacturing. Other technologies that can also improve manufacturing are intelligent agents, the World Wide Web and Virtual Reality. The impact of these new technologies is addressed in the next two subsections. In the application area side, to give a realistic view of current manufacturing systems, future systems should consider environment, health and safety issues.

Table 2: Summary of the papers referred to in this paper classified by manufacturing processes and AI technique used

\begin{tabular}{|c|c|c|c|c|c|c|}
\hline & Design & $\begin{array}{l}\text { Process } \\
\text { Planning }\end{array}$ & Quality & $\begin{array}{l}\text { Maintenance \& } \\
\text { Diagnosis }\end{array}$ & Control & Scheduling \\
\hline $\begin{array}{l}\text { Knowledge- } \\
\text { based } \\
\text { Systems }\end{array}$ & $\begin{array}{l}\text { Basu et all. } \\
\text { (95), Chon et } \\
\text { al. }(93), \text { Mitra } \\
\text { et all. (93), }\end{array}$ & $\begin{array}{l}\text { Eskicioğlu } \\
\text { (92), Pande } \\
\text { \& Desai } \\
\text { (95), Wong }\end{array}$ & $\begin{array}{l}\text { Desl\&res \& } \\
\text { Pierreval } \\
(95)\end{array}$ & $\begin{array}{l}\text { Arslan et all. } \\
\text { (93), Batanov et } \\
\text { all. }(93), \text { Clark et } \\
\text { all. }(92),\end{array}$ & & $\begin{array}{l}\text { Zhang \& } \\
\text { Chen (99) }\end{array}$ \\
\hline
\end{tabular}




\begin{tabular}{|c|c|c|c|c|c|c|}
\hline & $\begin{array}{l}\text { Rowland \& } \\
\text { Jain (93), } \\
\text { Smith \& } \\
\text { Midha, (99), }\end{array}$ & $\& \operatorname{Siu}(95)$ & & $\begin{array}{l}\text { Fujikawa \& Ishii } \\
\text { (95), Kobbacy } \\
\text { (92), Pandelidis } \\
\text { \& Kao (90), } \\
\text { Rowland \& Jain } \\
\text { (93) }\end{array}$ & & \\
\hline $\begin{array}{l}\text { Neural } \\
\text { Networks }\end{array}$ & $\begin{array}{l}\text { Christodoulou } \\
\& \text { Gaganis } \\
\text { (98), } \\
\text { Gunasekera et } \\
\text { all. (98), } \\
\text { Gunes et all. } \\
\text { (99), Kusiak } \\
\text { \& Lee (96), } \\
\text { Rao \& Gu } \\
\text { (95), }\end{array}$ & Dimla (99) & $\begin{array}{l}\text { Chinnan \& } \\
\text { Kolarik, (97), } \\
\text { Guh \& } \\
\text { Tannock } \\
\text { (99), Zhang } \\
\text { et all. (96) }\end{array}$ & $\begin{array}{l}\text { Chang \& Ho } \\
\text { (99), } \\
\text { Dedeakayogullari } \\
\text { \& Buma (99), Ho } \\
\text { \& Chang (99), } \\
\text { Kim \& Kumara } \\
\text { (97), Lin et all. } \\
\text { (95b), Ransing \& } \\
\text { Lewis (97), Su et } \\
\text { all. (95), Tien \& } \\
\text { Chang (99), } \\
\text { Wang \& Huang } \\
\text { (97), Wei (99) }\end{array}$ & $\begin{array}{l}\text { Acosta et all. } \\
\text { (99), Hall \& Lu } \\
\text { (1992), Hao et } \\
\text { all. (95), Sung } \\
\text { \& Choung, (99) }\end{array}$ & $\begin{array}{l}\text { Chen \& } \\
\text { Muraki (97), } \\
\text { Grabot (98), } \\
\text { Rovithakis } \\
\text { et all. (99) }\end{array}$ \\
\hline $\begin{array}{l}\text { Fuzzy } \\
\text { Logic }\end{array}$ & $\begin{array}{l}\text { Babuska et } \\
\text { all. (99), Ip, } \\
\text { (98), Masnata } \\
\& \text { Settinesi } \\
\text { (97), }\end{array}$ & $\begin{array}{l}\text { Dweiri \& } \\
\text { Meier (96) }\end{array}$ & $\begin{array}{l}\text { Chan et al. } \\
\text { (99), Chan } \\
\text { \&. Lau (99), } \\
\text { Fung et al. } \\
\text { (99), } \\
\text { Glushkovsky, } \\
\& \text { Florescu, } \\
\text { (96), } \\
\text { Gutierrez \& } \\
\text { Carmona } \\
\text { (95), Khoo \& } \\
\text { Ho. (96), } \\
\text { Wang \& } \\
\text { Chen, (95), } \\
\text { Wang (99), } \\
\text { Yongting } \\
\text { (96) }\end{array}$ & Khoo et all. (99) & $\begin{array}{l}\text { Caprihan et all. } \\
\text { (97) }\end{array}$ & $\begin{array}{l}\text { Shipley et } \\
\text { all. (96), Yu } \\
\text { et all. (99) }\end{array}$ \\
\hline $\begin{array}{l}\text { Genetic } \\
\text { Algorithms }\end{array}$ & $\begin{array}{l}\text { Bos (98), } \\
\text { Scott et all. } \\
\text { (99), }\end{array}$ & $\begin{array}{l}\text { Bhaskara } \\
\text { Reddy et all. } \\
\text { (99), Dutta } \\
\text { \& Yip-Hoi } \\
\text { (96), Gupta } \\
\text { et all. (96), } \\
\text { Hamamoto et } \\
\text { all. (99), } \\
\text { Morad \& } \\
\text { Zalzala (99), } \\
\text { Rajasekharan } \\
\text { et all. (97), } \\
\text { Rao et all. } \\
\text { (99), Suresh } \\
\text { et all. (95), } \\
\text { Tam \& Chan } \\
\text { (98) }\end{array}$ & $\begin{array}{l}\text { Gill \& Bector } \\
\text { (97), Vancza } \\
\& \text { Markus } \\
\text { (91) }\end{array}$ & $\begin{array}{l}\text { Fushuan \& } \\
\text { Chang (98), } \\
\text { Garrell et all. } \\
\text { (99), Rojas- } \\
\text { Guzman \& } \\
\text { Kramer (94) }\end{array}$ & $\begin{array}{l}\text { Lennon \& } \\
\text { Passino (99), } \\
\text { Ong \& Khoo } \\
\text { (99) }\end{array}$ & $\begin{array}{l}\text { Candido et } \\
\text { all. (98), } \\
\text { Jawahar et } \\
\text { all. (98), } \\
\text { Lam et al. } \\
\text { (99), Min \& } \\
\text { Cheng (99), } \\
\text { Uckun et all. } \\
\text { (93), } \\
\text { Webster et } \\
\text { all. (98) }\end{array}$ \\
\hline $\begin{array}{l}\text { Case-based } \\
\text { Reasoning }\end{array}$ & $\begin{array}{l}\text { Bose (97), } \\
\text { Gao et all. } \\
\text { (98), Hua et } \\
\text { all. (96), } \\
\text { Manfaat (97), } \\
\text { Purvis \& Pu }\end{array}$ & $\begin{array}{l}\text { Ben-Arieh \& } \\
\text { Chopra (97), } \\
\text { Champati et } \\
\text { all. (96) }\end{array}$ & $\begin{array}{l}\text { Malek et } \\
\text { al.(98) }\end{array}$ & Xia \& Rao (99) & & $\begin{array}{l}\text { Coello \& } \\
\text { DosSantos. } \\
\text { (99), } \\
\text { Cunningham } \\
\text { \& Smyth } \\
\text { (1997), }\end{array}$ \\
\hline
\end{tabular}




\begin{tabular}{|c|c|c|c|c|c|}
\hline & $\begin{array}{l}\text { (98), Sun \& } \\
\text { Chen (95), } \\
\text { Zeid et all. } \\
\text { (97), Shii, } \\
\text { (97) }\end{array}$ & & & & $\begin{array}{l}\text { MacCarthy } \\
\& \text { Jou (96) }\end{array}$ \\
\hline $\begin{array}{l}\text { Hybrid } \\
\text { Systems }\end{array}$ & $\begin{array}{l}\text { Chen } \text { et } \\
\text { all.(98), Lee } \\
\text { et al. (99), } \\
\text { Shivathaya \& } \\
\text { Fang (99), }\end{array}$ & $\begin{array}{l}\text { Ettl \& } \\
\text { Schwehm } \\
\text { (95), } \\
\text { Kobbacy \& } \\
\text { Liang (99), } \\
\text { Malakooti et } \\
\text { all. (95), } \\
\text { Ming et all. } \\
\text { (99), Rixen } \\
\text { et all. (95) }\end{array}$ & $\begin{array}{l}\text { Leger et all. (98), } \\
\text { Wen and Chang } \\
\text { (99), Kobbacy } \\
\text { (92), Kobbacy et } \\
\text { all. (95), Zhang } \\
\text { \& Jardine(97), } \\
\text { Labib et al. (98) }\end{array}$ & $\begin{array}{l}\text { Filipic et all. } \\
\text { (99), Ortega \& } \\
\text { Giron-Sierra } \\
\text { (98), Santa et } \\
\text { al. (99), Suresh } \\
\text { et all. (99), } \\
\text { Vishnupad, } \\
\text { (96) }\end{array}$ & $\begin{array}{l}\text { Kim et all. } \\
\text { (98), Lee, et } \\
\text { all. (98), } \\
\text { Szelke \& } \\
\text { Markus (97) }\end{array}$ \\
\hline
\end{tabular}

\section{Integration and Intelligent Agents}

Much of the work on intelligent systems is at a research and prototype stage, and so is naturally on a relatively small scale. A danger of isolated small-scale efforts is a tendency to compartmentalise the operations area and as a result design systems which aim for local solutions to sub-problems. Rodd (1992) and Kopacek (1999) state that integration will be the main task facing manufacturing systems in the future. Some attempts are made to integrate some components of the manufacturing system. There is some work on the integration of computer-integrated process planning and scheduling (Aldakhilallah and Ramesh (1999), Morad and Zalzala (1999). Morad and Zalzala have integrated process planning and scheduling using genetic algorithms. The scheduling problem is extended to include process planning. The scope of consideration of the alternative machines includes different capabilities and cost to operate, as well as different capabilities and cost to operate and different processing times. The scheduling problem is formulated as a multi-objective problem with the objectives of minimising makespan, minimising total number of rejects and minimising total processing cost.

Intelligent agents are seen as the solution for integration (Kopacek, 1999). Intelligent agents are used in distributed AI. They allow the co-ordination of local AI systems distributed throughout the manufacturing process (i.e. production, scheduling, inventory and maintenance etc.) and through the business as a whole (e.g. marketing, product design, operations, finance and personnel etc.). Negotiation between the separate AI systems, each with their own set of local optima or preferences, enables the selection of policies more closely aligned to the objectives of the manufacturing function and /or business as a whole (example, Lee and Lau, 1999). AARIA project (Baker et al., 1999) explores how agent technology can combine distribution with the Internet's global communications infrastructure to make virtual manufacturing more cost-effective than existing, centrally managed operations. Mutarana et al. (1999), proposed MetaMorph, an adaptive agent based architecture for intelligent manufacturing.

\section{Advance in technology}

The world Wide Web (WWW) represents one of the most important challenges in the emerging information society. Many organisations and companies have turned to the WWW to sell and promote their product. The WWW is seen 
as the future window shopping for businesses. This new approach to business is commonly known as E-Commerce. The WWW is also promising for distributed manufacturing.

Virtual manufacturing is another new approach to manufacturing. It requires a robust information infrastructure that comprises rich information models for products, processes and production systems. The decreasing costs of hardware have made virtual environments increasingly popular and are used in many fields. Virtual reality (VR) can be applied for most components of the manufacturing process. In design VR will support detailed and accurate design activities and will provide sophisticated means of manipulating shape and form represented by the virtual models. Nakayasu et al. (1999) have used VR for design and production of metal sheet. Virtual manufacturing (VM) is expected to support assessing the manufacturability of a candidate design and to provide accurate estimates for processing times, cycle times and costs as well as product quality. This is because VM will be able to model both the processes employed for the product's manufacture and the production process (Lin, 1995). VM may play a significant role in distributed manufacturing and is expected to support distributed design. VM can provide details and information about, process, production, and shop floor control to be shared over networks.

From the hardware side, computer performances keep improving and this will result in more powerful applications and automations in manufacturing. Robots will be needed and the research in robotics will be dominated by two directions (Kopacek, 1999). Additional features such as combined force and position control, external sensors based on microsystems, flexible and lightweight structures need to be added to robots used in classical applications. Another type of robot that need to be developed for the next generation are service robots. Service robots are characterised by the following facilities: mobility, portability, operating case, sensing, learning, judging function and adaptability (Kopacek, 1999). In an invited paper, Burdea(1999), reviewed how robotics and VR can be integrated . VR-enhanced CAD design, robot programming, and plant layout simulation were considered.

\section{Environment, Health and Safety}

Back in 1989, clean manufacturing was one of the six cases defined by the Intelligent manufacturing initiative (Kopacek, 1999). Recently, concern for the environment has led many manufacturing industries to take a proactive role in clean manufacturing. Sustainable development, where the waste from one process becomes the raw material for another, is used to achieve clean manufacturing (Young et al., 1997). Tools to help manufacturing engineers and environmental reviewers to assess the consequences of their manufacturing decisions are also developed, example Eco_Sys ( Kleban et al., 1996). Work on process planning for environmentally conscious machining can be found in (Srinivasan and Sheng, 1999a and b).

There are more than 60 acts of parliament and about 400 sets of regulations that are relevant to health and safety at work in the UK (The Royal Institution of Chartered Surveyors, 1997). The proper application of these acts and regulations by use of intelligent systems will influence future manufacturing systems. Health and Safety should therefore be introduced and taken into account in any manufacturing model in the future. 
To conclude, this review shows that the use of AI in design, planning, quality management, maintenance, control, and scheduling can result in significant gains in these particular component areas of manufacturing. The continuing demands of the manufacturing industry will necessitate the development of AI to facilitate more integrated, and holistic manufacturing systems.

\section{REFERENCES}

Acosta, L., Marichal, G.N., Moreno, L., Rodrigo, J.J, Hamilton, A., Mendez, J.A (1999), “A robotic system based on neural network controllers", Artificial Intelligence in Engineering, 13(4), pp. 393-398

Aldakhilallah, K.A. and Ramesh, R. (1999), "Computer-integrated process planning and scheduling (CIPPS): intelligent support for product design, process planning and control”, International Journal of Production Research, 37(3), pp. 481-500.

Alting, L. and Zhang, H.C. (1989), “Computer aided process planning: the state of the art survey", International Journal of Production Research, vol.27, pp. 553-585.

Arslan, T.S., Bottaci, L. and Taylor, G.E. (1993), "A fault dictionary based expert system for failure diagnosis in a multiple-PCB environment”, Engineering Applications of Artificial Intelligence, 6(5), pp. 447-456.

Azlan, H.M. (1999), "Review of the applications of neural networks in chemical process control - simulation and online implementation", Artificial Intelligence in Engineering , 13(1), pp. 55-68

Babuska, R., Verbruggen H.B. and Van Can, H.J.L.(1999), "Fuzzy modeling of enzymatic penicillin-G conversion”, Engineering Applications of Artificial Intelligence,12(1), pp. 79-92.

Baker, A.D., Parunak, H.V. and Erol, K. (1999), “Agents and the Internet: Infrastructure for mass customization”, IEEE Internet Computing, 3(5), pp.62-69

Batanov, D.B., Nagarur, N. and Nitikhunkasem, P. (1993), "EXPERT-MM: A knowledge-based system for maintenance management", Artificial Intelligence in Engineering, Vol. 8, pp.283-291.

Batanov D.N. (1998), "Industrial applications of knowledge-based/expert systems", Computers in Industry 37(2), pp. $83-85$

Basu, A., Hyer, N. and Shtub, A. (1995), “An expert-system based approach to manufacturing cell design”, International Journal of Production Research, 33(10), pp.2739-2755

Ben-Arieh, D. and Chopra, M. (1997), “A case-based NC code generating system for prismatic parts", International Journal of Production Research, 35(7), pp. 1925-1944

Bhaskara Reddy, S.V., Shunmugam, M.S. and Narendran, T.T. (1999), "Operational sequencing in CAPP using genetic algorithms”, International Journal of Production Research, 37(5), pp. 1063-1074.

Borchelt, R.D. and Thorson, J. (1997), “Toward reusable hierarchical cell control software”, International Journal of Production Research, 35(2), pp. 577-594.

Bos, A.H.W (1998), “Aircraft conceptual design by genetic/gradient-guided optimization”, Engineering Applications of Artificial Intelligence, 11(3), pp. 377-382.

Bose, A., Gini, M. and Riley, D. (1997), “A case-based approach to planar linkage design”, Artificial Intelligence in Engineering, 11(2), pp. 107-119

Burdea, G.C. (1999), "Invited review: The synergy between virtual reality and robotics", IEEE Transactions on Robotics and Automation, 15(3), pp.400-410. 
Candido, M.A.B., Khator, S.K, and Barcia, R.M. (1998), "A genetic algorithm based procedure for more realistic job shop scheduling problems", International Journal of Production Research, 36(12), pp. 3437-3457

Caprihan, R., Kumar, S. and Wadhwa, S. (1997), "Fuzzy systems for control of flexible machines operating under information delays", International Journal of Production Research, 35(5), pp. 1331-1348.

Chakraborty, T.K. (1992), "A class of single sampling plans based on fuzzy optimisation”, Operations Research, 25(4), pp. 11-20

Chakraborty, T.K. (1994), "A class of single sampling inspection plans based on possibilistic programming problem”, Fuzzy Sets and Systems, 63(1), pp. 35-43.

Champati, S., Lu, W.F., and Lin, A.C. (1996), “Automated operation sequencing in intelligent process planning: a CBR Approach”, The International Journal of Advanced Manufacturing Technology, 12(1), pp. 21-36

Chan, L.K., Kao, H.P., Ng, A. and Wu, M.L. (1999), "Importance of customer needs in quality function deployment by fuzzy and entropy methods", International Journal of Production Research, 37(11), pp. 2499-2518.

Chan, C.W. and Lau, P. (1999), "Representing user preference in engineering design domains using an enhanced weighted fuzzy reasoning algorithm”, Artificial Intelligence in Engineering, 13(1), pp.1-10

Chen, W. and Muraki, M. (1997), “An action strategy generation framework for an on-line scheduling and control system in batch processes with neural networks", International Journal of Production Research, 35(12), pp. 34833507

Coello, J.M.A. and DosSantos, R.C. (1999), "Integrating CBR and heuristic search for learning and reusing solutions in real-time task scheduling", Lecture Notes In Artificial Intelligence, Vol.1650, pp.89-103

Cunningham, P. and Smyth, B. (1997), "Case-based reasoning in scheduling: reusing solution components", International Journal of Production Research, 35(11), pp. 2947-2962

Hang, S.I., Tsujimura, Y. Gen, M. and Tozawa, T. (1995), “An efficient approach for large scale project planning based on fuzzy Delphi method”, Fuzzy Sets and Systems, 76(2), pp. 277-288.

Chang, S.I. and Ho, E.S. (1999), “A two-stage neural network approach for process variance change detection and classification”, International Journal of Production Research, 37(7), pp. 1581-1599.

Chen, N., Li, C. and Qin, P. (1998), "KDPAG expert system applied to materials design and manufacture", Engineering Applications of Artificial Intelligence, 11(5), pp. 669-674.

Chinnan, R.B. and Kolarik, W.J. (1997), "Neural network-based quality controllers for manufacturing systems", International Journal of Production Research, 35(9), pp. 2601-2620.

Christodoulou, M. and Gaganis, V. (1998), "Neural networks in manufacturing cell design", Computers in Industry 36(1-2), pp. 133-138.

Chon, Y., Kim, K.I. and Kim, K. (1993), “A knowledge-based system for centrifugal fan blade design”, Engineering Applications of Artificial Intelligence, 6(5), pp. 425-435.

Clark, G., Mehta, P. and Thomson, T. (1992), "Application of knowledge-based systems to optimised building management maintenance", Lecture Notes in Artificial Intelligence, Vol. 604, pp.69-78.

Dean, B.R., Hand, S. and Kaye, M. (1997), “A cost based strategy for assessing improvements in manufacturing processes", International Journal of Production Research, 35(4), pp. 955-968

Dedeakayogullari, I. and Buma, K.N. (1999), “The determination of mean and/or variance shifts with artificial neural networks", International Journal of Production Research, 37(10), pp. 2191-2200. 
Dekker, R. (1996), "Applications of maintenance optimization models: a review and analysis", Reliability Engineering and System Safety, Vol. 51, pp.229-240.

Deslandres, V. and Pierreval, H. (1995), "SYSMIQ - A Knowledge-based system for assisting quality-control”, International Journal of Production Research, 33(5), Pp.1201-1212

Dhaliwal, D.S. (1986), "The use of AI in maintaining and operating complex engineering systems, in :Mamdani, A. and Pstachion, J.E. (eds.), Expert Systems and Optimisation in Process Control, Gower technical Press: Aldershot, UK, pp28-33.

Dimla, S. (1999), "Application of perceptron neural networks to tool-state classification in a metal-turning operation”, Engineering Applications of Artificial Intelligence, 12(4), pp. 471-477

Dutta, D. and Yip-Hoi, D. (1996), "A genetic algorithm application for sequencing operations in process planning for parallel machines", IIE Transactions, 28, pp. 55-68.

Dweiri, F. and Meier, F.A. (1996), “Application of fuzzy decision making in facilities layout planning”, International Journal of Production Research, 34(11), pp. 3207-3225.

Ebrahimi, M., and Whalley, R. (1998), "Machine tool syntheses in virtual machining”, International Journal of Materials \& Product Technology, 13(3-6), pp.301-312

Eskicioğlu, H. (1992), “The use of expert systems building tools in process planning”, Engineering Applications of Artificial Intelligence, 5(1), pp. 33-42

Ettl, M. and Schwehm, M. (1995), "Determining the optimal partition and kanban allocation in JIT production lines”, In: Biethahan, J. and Nissen, V. (eds.). Evolutionary Algorithms in Management Applications, Springer: Berlin, pp. 139-152.

Fielder, K. Galletly, J.E. and Bicheno, J. (1993), “Expert advice for JIT implementation”, International Opns \& Production Management, 13 (6), pp. 23-30.

Filipic, B., Urbancic, T. and Krizman, V. (1999), “A combined machine learning and genetic algorithm approach to controller design”, Engineering Applications of Artificial Intelligence, 12(4), pp. 401-409

Frank, P.M. and Koppen-Seliger, B. (1997), "New developments of AI in fault diagnosis", Engineering Applications of Artificial Intelligence, 10(1), pp. 3-14.

Fujikawa, S. and Ishii, K. (1995), "Diagnostic expert systems for defect in forged parts", Journal of Intelligent Manufacturing, 6(3), pp. 163-1733.

Fung, R.Y.K., Popplewell, K. and Xie, J. (1997), “An intelligent hybrid system for customer requirements analysis and product attribute targets determination", International Journal of Production Research, 36(1), pp. 13-34

Fung, R.Y.K. and Popplewell, K. (1997), "An intelligent fuzzy inference model for customer requirements management", in Kobbacy K.A.H., Vadera S. and Proudlove N.C (Eds.), Proceeding of the First European Conference on Intelligent Manufacturing Systems in Operation, Operational Research Society: Birmingham, pp. 145-153.

Fung, R.Y.K., Law, D.S.T. and Ip, W.H. (1999), "Design targets determination for inter-dependent product attributes in QFD using fuzzy inference", The International Journal of Manufacturing Technology Management, 10(6), pp. 376-383.

Fushuan, W. and Chang, C.S. (1998), “A new approach to fault diagnosis in electrical distribution networks using a genetic algorithm”, Artificial Intelligence in Engineering , 12(1-2), pp. 69-80

Garrell, J.M., Guiu, I., Golobardes, E., Ribe, I., Bernardo, E., Mansilla, I., Llora, X. and Fabrega, I. (1999), "Automatic diagnosis with genetic algorithms and case-based reasoning", Artificial Intelligence in Engineering, 13(4), pp. 367-372 
Gao, Y.S., Zeid, I. and Bardasz, T. (1998), "Characteristics of an effective design plan system to support reuse in case-based mechanical design”, Knowledge-Based Systems, 10(6), pp.337-350

Gazen, C. and Ersoy, C. (1999), "Genetic algorithms for designing multihop lightwave network topologies", Artificial Intelligence in Engineering, 13(3), pp. 211-221.

Gill, A. and Bector, C.R. (1997), “A fuzzy linguistic approach to data quantification and construction of distance measures for the part family formulation problem", International Journal of Production Research, 35(9), pp. 25652578 .

Glushkovsky, E.A. and Florescu, R.A. (1996), "Fuzzy sets approach to quality improvement", Quality and Reliability, 12(1), pp. 27-37.

Goldberg, D. (1989), Genetic Algorithms in Search, Optimization, and Machine Learning, Addison-Wesley: Reading, MA

Grabot, B. (1998), “Objective satisfaction assessment using neural nets for balancing multiple objectives", International Journal of Production Research, 36(9), pp. 2377-2395

Guh, R.S. and Tannock, J.D.T. (1999), "Recognition of control chart concurrent patterns using a neural network approach", International Journal of Production Research, 37(8), pp. 1745-1765.

Guh, R.S., Zorriassatine, F., Tannock, J.D.T and O'Brien, C. (1999), "On-line control chart pattern detection and discrimination - a neural network approach", Artificial Intelligence in Engineering, 13(4), pp.413 - 425

Guiffrida, A.L. and Nagi, R. (1998), "Fuzzy set theory applications in production management research: a literature survey", Journal of Intelligent Manufacturing, 9(1), pp. 39-59.

Gunasekera, J.S., Jia, Z., Malas, J.C. and Rabelo, L. (1998), "Development of a neural network model for a cold rolling process”, Engineering Applications of Artificial Intelligence, 11(5), pp. 597-603.

Gunes, F., Torpi, H., Cetiner, B.A. (1999), "Neural network modeling of active devices for use in MMIC design", Artificial Intelligence in Engineering, 13(4), pp.385-392

Gupta, Y., Gupta, M., Kumar, A. and Sundaram, C. (1996), "A genetic algorithm-based approach to cell composition and layout design problems”, International Journal of Production Research, 34(2), pp.447-482

Gutierrez, I. and Carmona, S. (1995), “Ambiguity in multicriteria quality decisions", International Journal of Production Economics, 38(2/3), pp. 2215-224.

Gurney, K. (1997), An introduction to neural networks, UCL Press.

Hall, J.W. and Lu, S.C.Y. (1992), "Emulating human process control functions with neural networks", Annual Report, Knowledge-based engineering research laboratory, University of Illinois, pp41-48.

Hamamoto, S. Yih, Y. and Salvendy, G. (1999), "Development and validation of genetic algorithm based facility layout - a case study in the pharmaceutical industry", International Journal of Production Research, 37(4), pp. 749768.

Hao, G., Shang, J.S. and Vargas, L.G. (1995), “A neural-network model for online control of flexible manufacturing systems", International Journal of Production Research, 33(10), pp.2835-2854

Ho, E.S. and Chang, S.I. (1999), “An integrated neural network approach for simultaneous monitoring of process mean and variance shift - a comparative study", International Journal of Production Research, 37(8), pp. 18811901 .

Hosseini, J., Baharaeen, S. and Zhenf, X.T. (1988), "Design of knowledge based system for inventory control”, Journal of Engineering Computing and Application, pp.28-35. 
Hua, K., Faltings, B. and Smith, I. (1996), "CADRE: case-based geometric design", Artificial Intelligence in Engineering , 10(2), pp.171-183

Ip, W.L.R. (1998), “A fuzzy basis material removal optimization strategy for sculptured surface machining using ball-nosed cutters", International Journal of Production Research, 36(9), pp. 2553-2571

Jamshidi M. (1997), Large scale systems: modeling, control and fuzzy logic, Prentice Hall.

Jawahar, N., Aravindan, P., Ponnambalam, S.G. and Karthikeyan, A. (1998), “A genetic algorithm-based scheduler for setup-constrained FMC", Computers in Industry, 35 (3), pp. 291-310

Jo, J.H. and Gero, J.S. (1998), "Space layout planning using an evolutionary approach", Artificial Intelligence in Engineering, 12(3), pp. 149-162

Kanagawa, A. and Ohta, H. (1990), “A design for single sampling attribute plan based on fuzzy set theory”, Fuzzy Sets and Systems, 37(2), pp. 173-181.

Kanagawa, A., Tamaki, F. and Ohta, H (1993), "Control Charts for processing average and variability based on linguistics data”, International Journal of Production Research, 31(4), pp. 913-922.

Karafyllidis, I. (1999), "Design of a dedicated parallel processor for the simulation of the photolithography process using a genetic algorithm”, Engineering Applications of Artificial Intelligence, 12(4), pp. 411-427.

Karwowski, W. and Evans, G.W. (1986), "Fuzzy concepts in production management research: a review", International Journal of Production Management, 24(1), pp. 129-147

Khoo, L.P. and Ho, N.C. (1996), "Framework of a fuzzy quality function deployment", International Journal of Production Research, 34(2), pp. 299-311

Khoo, L.P., Ang, C.L. and Zhang, J. (1999), "An IDEF0 model-based intelligent fault diagnosis system for manufacturing systems", International Journal of Production Research, 37(1), pp. 35-48.

Kim, T. and Kumara, S.R.T. (1997), "Boundary defect recognition using neural networks", International Journal of Production Research, 35(9), pp. 2397-2412.

Kim, C.O., Min, H.S. and Yih, Y. (1998), "Integration of inductive learning and neural networks for multi-objective FMS scheduling”, International Journal of Production Research, 36(9), pp. 2497-2509.

Kiritsis, D. (1995), "A review of knowledge-based expert systems for process planning: methods and problems", International Journal of Advanced Manufacturing Technology, vol. 10 pp. 240-262.

Kleban, D.S., Luger, G.F. and Watkins, R.D. (1996), "Expert system support for environmental assessment of manufacturing products and facilities", Journal of Intelligent Manufacturing, 7(1), pp. 39-53

Klir, G. and Yuan, B. (1995), Fuzzy Sets and Fuzzy Logic: Theory and Applications, Prentice-Hall, New Jersey.

Kobbacy, K.A.H. (1992), "The use of knowledge-based systems in evaluation and enhancement of maintenance routines”, International Journal of Production Economics, Vol.24, pp.243-248.

Kobbacy, K.A.H., Proudlove, N.C. and Harper, M.A. (1995), "Towards an intelligent maintenance optimisation system”, Journal of the Operational Research Society, Vol.46, pp.831-853.

Kobbacy, K.A.H. and Liang, Y. (1999), "Towards the development of an intelligent inventory management system”, Journal of Integrated Manufacturing Systems, 10(6), pp. 354-366.

Kolodner, J. (1993), Case-Based Reasoning, Morgan Kaufman: San Mateo, CA.

Kopacek, P. (1999), "Intelligent Manufacturing: Present States and Future Trends", Journal of Intelligent and Robotic Systems, 26(3-4), pp. 217-229. 
Kouvelis, P. (1992), "Design and planning problems in flexible manufacturing systems: a critical review", Journal of Intelligent Manufacturing, 3(2), pp. 75-99.

Kumar, B., Raphael, B. (1997), "Reconstructive memory in case-based design", Artificial Intelligence in Engineering, 11(3), pp. 245-258

Kumara, S.R.T and Kamarthi, S.V. (1991), "Function to structure transformation in conceptual design: an association memory-based paradigm", Journal of Intelligent Manufacturing, 2(5), pp. 281-292.

Kuo, T. and Mital, A. (1993), "Quality control expert systems; a review of pertinent literature", Journal of Intelligent Manufacturing, 4(4), pp. 245-257.

Kuo, R.J. and Xue, K.C. (1998), "An intelligent sales forecasting system through integration of artificial neural network and fuzzy neural network", Computers in Industry, 37 (1), pp.1-15

Kuo, R.J. and Cohen, P.H. (1998), "Intelligent tool wear estimation system through artificial neural networks and fuzzy modeling”, Artificial Intelligence in Engineering, 12(3), pp. 229-242

Kusiak, A. and Lee, H. (1996), "Neural computing-based design of components for cellular manufacturing", International Journal of Production Research, 34(7), pp. 1777-1790.

Labib, A. W., Williams, G. B., and O'Conner, R. F. (1998), “An intelligence model (system): An application of A.H.P. and fuzzy logic rule-based controller", Journal of the Operational Research Society, Vol. 49, pp745-757.

Lam, F.S., Lin, B.C., Sriskandarajah, C. and Yan, H. (1999), "Scheduling to minimize product design time using a genetic algorithm", International Journal of Production Research, 37(6), pp.1369-1386

Lee, C.Y. Piramuthu, S. and Tsai, Y.K. (1998), "Job shop scheduling with a genetic algorithm and machine learning", International Journal of Production Research, 35(4), pp. 1171-1191

Lee, W.B. and Lau, H.C.W. (1999), "Multi-agent modeling of dispersed manufacturing networks", Expert Systems with Applications, 16(3), pp.297-306

Lee, Y.H., Yang, B.H; and Moon, K.S. (1999), "An economic machining process model using fuzzy non-linear programming and neural network", International Journal of Production Research, 37(4), pp. 835-847

Leger, R.P, Garland, W.M.J, and Poehlman, W.F.S (1998), "Fault detection and diagnosis using statistical control charts and artificial neural networks", Artificial Intelligence in Engineering, 12(1-2), pp. 35-47

Lennon, W.K. and Passino, K.M (1999), "Genetic adaptive identification and control”, Engineering Applications of Artificial Intelligence, 12(2), pp. 185-200.

Lin, E., Minis, I. Nau, D.S. and Regli, W.C. (1995a), "Contribution to Virtual Manufacturing Background Research", http://www.isr.umd.edu/Labs/CIM/vm/report/report.html

Lin, H., Yih, Y. and Salvendy, G. (1995b), "Neural network based fault diagnosis of hydraulic forging presses in China", International Journal of Production Research, 33(7), pp. 1939-1951.

Luxhoj, J.T., Agnihotri, D. Kazunas, S. and Nambiar, S. (1993), "A proposed knowledge based system (KBS) for selection of inventory control policies", International Journal of Production Research, 31(7), pp. 1709-1720.

MacCarthy, B.L. and Jou, P. (1996), "Case-based reasoning in scheduling", in: Khan MK, Weright, C.S. and Whalley, R. (eds.), Proceedings of the Advanced Manufacturing Processes, Systems and Technologies Conference, Mechanical Engineering publications UK, pp. 211-218

Maiers, J. and Sherif, Y.S. (1985), "Application of fuzzy set theory", IEEE Transactions on Systems, Man and Cybernetics, 15(1), pp. 175-189. 
Maki, N., Tabe, T and Salvendy, G. (1997), "Design and utilization of a fuzzy knowledge-based system for design feature recognition of freehand illustrations", International Journal of Production Research, 35(1), pp. 17-28

Malakooti,B.B., Zhou, Y.Q and Tandler, E.C (1995). In-process regressions and adaptive multicriteria neural networks for monitoring and supervising machining operations, Journal of Intelligent Manufacturing, 6(1), pp.53- 66

Malek, M., Toitgans, M.P., Wybo, J.L. and Vincent, M.(1998), “An operator support system based on case-based reasoning for the plastic moulding injection process", Lecture Notes In Artificial Intelligence, Vol.1488, pp.402-413

Manfaat, D. (1997), “Case-Based Reasoning in Design”, Artificial Intelligence in Engineering 11(1), 61-62

Masnata, A. and Settinesi L. (1997), “An application of fuzzy clustering to cellular manufacture”, International Journal of Production Research, 35(4), pp. 1077-1094.

Maturana, F., Shen, W. and Norrie, D.H. (1999), "MetaMorph: an adaptive agent-based architecture for intelligent manufacturing", International Journal of Production Research, 37(10), pp. 2159-2173.

Mauridou, T. and Pardalos, P.H. (1997), "Simulated annealing and genetic algorithms for the facility layout problem: a survey”, Computational Applications, 7, pp. 111-126.

Mehrotra, K., Mohan, C.K. and Ranka, S. (1997), Elements of Artificial Neural Networks, The MIT Press, Massachusetts

Mellado, M., Vendrell, E., Crespo, A., Lopez, P., Garbajosa, J., Lomba, C., Schilling, K., Stutzle, H., and Mayerhofer, R.(1999), "Application of a real time expert system platform for flexible autonomous transport in industrial production”, Computers in Industry, 38(2), pp. 187 - 200

Min L., Cheng W. (1999), "A genetic algorithm for minimizing the makespan in the case of scheduling identical parallel machines”, Artificial Intelligence in Engineering, 13(4), pp.399-403

Ming , X.G., Mak, K.L. and Yan, J.Q. (1999), “A hybrid intelligent inference model for computer aided process planning”, The International Journal of Manufacturing Technology Management, 10(6), pp. 343-353.

Mitra, S. Basu, P. and Ghoshal, T.K. (1993), "Classification and representation of design knowledge for circulating fluidized bed boiler”, Engineering Applications of Artificial Intelligence, 6(5), pp. 457-464.

Morad, N. and Zalzala, A.M.S. (1999), "Genetic algorithms in integrated process planning and scheduling”, Journal of Intelligent Manufacturing, 10(2), pp. 169-179.

Nakayasu, H., Nakagawa, M., Ishikawa, K., Nakamachi, E., Nakamura, Y. and Katayama, T. (1999), "Design of die geometry for metal sheet forming in virtual manufacturing”, International Journal of Industrial Engineering-Theory Applications and Practice, 6(4), pp.271-281.

Nevins, J.L. and Whitney, D.E. (1989), Concurrent design of products and processes, McGraw-Hill, New York.

Nissen, V. and Biethahn, J. (1995), “An introduction to evolutionary algorithms”, In: Biethahm, J. and Nissen, V. (eds), Evolutionary Algorithms in Management Applications, Springer: Berlin, pp. 7-43.

Ong, N.S., and Khoo, L.P. (1999), “Genetic algorithm approach in PCB assembly", Integrated Manufacturing Systems, 10(5), pp. 256-265.

Ortega, G. and Giron-Sierra J.M. (1998), "Geno-fuzzy control in autonomous servicing of a space station", Engineering Applications of Artificial Intelligence, 11(3), pp. 383-400.

Pande, S.S. and Desai, V.S. (1995), "Expert CAPP system for single spindle automates", International Journal of Production Research, 33(3), pp.819-833 
Pandelidis, I.O. and Kao, J.F. (1990), "DETECTOR: a knowledge based system for injection molding diagnostics", Journal of Intelligent Manufacturing, 1, pp. 49-58.

Parlar, M. (1989), “EXPIM: a knowledge-based expert system for production/inventory modelling”, International Journal of Production Research, 27(1), pp.101-118.

Peres, C.R., Haber Guerra, R.E., Haber R., Alique A. and Ros, S. (1999), "Fuzzy model and hierarchical fuzzy control integration: an approach for milling process optimization", Computers in Industry, 39(3), pp, 199-207

Pham, D.T and Oh, S.J. (1999), "Identification of plant inverse dynamics using neural networks", Artificial Intelligence in Engineering, 13(3), 309-320

Pham, D.T. and Karaboga, D. (1999), "Self-tuning fuzzy controller design using genetic optimisation and neural network modelling", Artificial Intelligence in Engineering, 13(2), 119-130

Pierre, S. (1993), "Application of Artificial intelligence techniques to computer network topology design", Engineering Applications of Artificial Intelligence, 6(5), pp. 465-472.

Proudlove, N.C., Vadera, S. and Kobbacy K.A.H., (1997), "Intelligent management systems in operations: a review", Journal of the Operational Research Society, 49(7), pp. 682-699.

Purvis, L, and Pu, P. (1998), "COMPOSER: A case-based reasoning system for engineering design", Robotica, 16(3), pp.285-295.

Rajasekharan, M. Peters, B.A. and Yang, T. (1997), "A genetic algorithm for facility layout design in flexible manufacturing systems", International Journal of Production Research, 36(1), pp. 95-110

Ransing, R.S. and Lewis, R.W. (1997), "A semantically constrained neural network for manufacturing diagnosis", International Journal of Production Research, 35(9), pp. 2639-2660.

Rao, M., Wang, Q. and Cha, J. (1993), Integrated distributed intelligent systems in manufacturing, Chapman \&Hall.

Rao, H.A. and Gu, P. (1995), "A Multi-constraint neural-network for the pragmatic design of cellular manufacturing systems", International Journal of Production Research, 33(4), pp.1049-1070

Rao, H.A., Pham, S.N. and Gu, P. (1999), “A genetic algorithms-based approach for design of manufacturing systems: an industrial application”, International Journal of Production Research, 37(3), pp. 557-580.

Rasheed, K., Hirsh, H. and Gelsey, A. (1997), “A genetic algorithm for continuous design space search”, Artificial Intelligence in Engineering, 11(3), pp.295-305

Requicha, A.A.G. and Vandenbrande, J. (1988), “Automated system for process planning and part programming”, In AI: Implication for CIM, by Kusiak, A. (ed.), pp. 301-326, Kempston, UK.

Rixen, I, Bierwirth, C and Kopfer, H.(1995), A case study of operational just-in-time scheduling using genetic algorithms in management applications, Springer:Berlin, pp 112-123.

Rodd, M.G, Verbruggen, H.B, and Krijgsman, A.J.(1992), “Artificial intelligence in real-time control”, Engineering Applications of Artificial Intelligence, 5(5), pp. 385-399.

Rojas-Guzman, C. and Kramer, M.A. (1994), "Remote diagnosis and monitoring of complex industrial systems using a genetic algorithm approach", Proceedings of the 1994 IEEE International Symposium on Industrial Electronics, pp. 363-367.

Rovithakis, G.A., Gaganis V.I., Perrakis S.E. and, Christodoulou M.A. (1999), "Neuro schedulers for flexible manufacturing systems", Computers in Industry, 39(3), pp, 209-217

Rowland, J.G. and Jain L.C. (1993), "Knowledge-based systems for instrumentation diagnosis, system configuration and circuit and system design", Engineering Applications of Artificial Intelligence, 6(5), pp. 437-446. 
Sandurkar, S. and Chen, W.(1999), "GAPRUS--genetic algorithms based pipe routing using tessellated objects", Computers in Industry, 38(3), 209-223

Santa, K., Fatikow, S. and Felso, G. (1999), "Control of microassembly-robots by using fuzzy-logic and neural networks", Computers in Industry, 39(3), pp. 219-227

Schreiber, A.T., Wielenga, D.J. and Breuker, J. (1993), KADS: A principled approach to knowledge based systems, Academic Press: London.

Scott, D.A., Karr, C.L. and Schinstock, D.E (1999), "Genetic algorithm frequency-domain optimization of an antiresonant electromechanical controller", Engineering Applications of Artificial Intelligence, 12(2), pp. 201-211.

Shauker, R and Vrat, P. (1999), "Some design issues in cellular manufacturing using the fuzzy programming approach", International Journal of Production Research, 37(11), pp. 2545-2563

Shi, Z.Z, Zhou, H. and Wang, J. (1997), “Applying case-based reasoning to engine oil design”, Artificial Intelligence in Engineering, 11(2), pp.167-172

Shipley, M.F., De Korvin, A. and Omer, K. (1996), "A fuzzy logic approach for determining expected values: a project management application”, Journal of the Operational Research Society, 47(4), pp. 562-569.

Shivathaya, S.S. and Fang, X.D. (1999), "Fuzzy-logic-based ranking of steel grades generated by material design KBS", Engineering Applications of Artificial Intelligence, 12(4), pp. 503-512

Shukla, C.S. and Chen, F.F. (1996), "The state of the art in intelligent real-time FMS control: a comprehensive survey", Journal of Intelligent Manufacturing, 7(6), pp. 441-455.

Sim, S.K. and Teo, M.Y. (1997), "Enhancing flexibility of vision-based robots using artificial neural network approach", Integrated Manufacturing Systems, 8(1), pp. 43-49.

Sinha, D., Ghiaseddin, N. and Matta, K.(1989), "Expert systems for inventory control management”, Computers and Industrial Engineering, 17(1-4), pp. 425-429.

Smith, A.E. (1991), "Predicting product quality with back propagation: a thermoplastic injection molding case", International Journal of Advanced Manufacturing Technology, 8, pp. 252-257.

Smith, L.N. and Midha, P.S. (1999), "A knowledge based system for optimum and concurrent design, and manufacture by powder metallurgy technology", International Journal of Production Research, 37(1), pp. 125-137.

Sobolewski (1996), "Multiagent knowledge based environment for concurrent engineering applications", Concurrent Engineering Research and Applications, 4, pp. 89-97.

Soon, T.H. (1997), "Intelligent simulation-based scheduling of workcells: an approach", Integrated Manufacturing Systems, 8(1), pp. 6-23.

Sousa, P. and Ramos, C. (1999), "A distributed architecture and negotiation protocol for scheduling in manufacturing systems", Computers in Industry, 38(2), pp. 103-113

Srinivasan and Sheng, P. (1999a), "Feature based process planning for environmentally conscious machining- Part I: Microplanning", Robotics and Computer Integrated Manufacturing, 15(3), pp. 257-270.

Srinivasan and Sheng, P. (1999b), "Feature based process planning for environmentally conscious machining- Part II: Macroplanning", Robotics and Computer Integrated Manufacturing, 15(3), pp. 271-281.

Su, C.T., Chang, C.A. and Tien, F.C. (1995), "Neural networks for precision measurement in computer vision systems", Computers in Industry, 27, pp. 225-236. 
Sun, S.H. and Chen, J.L. (1995), “A modular fixture design system based on case-based reasoning”, International Journal of Advanced Manufacturing Technology, 10(6), pp.389-395

Sung, C.S. and, Choung, Y.I. (1999), “A neural network approach for batching decisions in wafer fabrication”, International Journal of Production Research, 37(13), pp. 3101-3114.

Suresh, G., Vinod, V.V. and Sahu, S. (1995), “A Genetic algorithm for facility layout”, International Journal of Production Research, 33(12), pp.3411-3423

Suresh, N.C, Slomp, J. and Kaparthi, S. (1999), "Sequence-dependent clustering of parts and machines: a Fuzzy ART neural network approach", International Journal of Production Research, 37(12), pp.2793-2816

Szelke, E. and Markus, G A. (1997), "Learning reactive scheduler using CBR/L”, Computers in Industry, 33(1), pp.31-46.

Tam K. Y. and. Chan S. K (1998), "Solving facility layout problems with geometric constraints using parallel genetic algorithms: experimentation and findings", International Journal of Production Research, 36(12), pp. 32533272

The Royal Institution of Chartered Surveyors (1997), Industrial Engineering Projects, practice and procedures for capital projects in the engineering, manufacturing and process industries, E \& FN Spon.

Tien, F.C. and Chang, C.A. (1999), "Using neural networks for 3D measurement in stereo-vision inspection systems”, International Journal of Production Research, 37(9), pp. 1935-1948.

Tsoukalas, L.H. and Uhrig, R.E. (1997), Fuzzy and Neural Approaches in Engineering, John Wiley \& Sons.

Uckun, S, Bagchi, S. Kawammuar, K. and Miyabe, Y. (1993), "Managing genetic search in job shop scheduling”, IEEE Expert, October, pp. 15-24

Vancza, J. and Markus, A. (1991), “Genetic algorithms in process planning”, Computers in Industry, 17, pp. 181194.

Verduin, W.H. (1995), Better products faster, a practical guide to knowledge based systems for manufacturers, Irwin professional Publishers, New York.

Vishnupad, P. (1996), "Neuro-fuzzy control of complex manufacturing systems", International Journal of Production Research, 34(12), pp. 3291-3309.

Wang, R.C. and Chen, C.H. (1995), "Economic statistical np-control chart designs based on fuzzy optimisation", International Journal of Quality and Reliability Management, 12(1), pp. 82-92.

Wang, C. and Huang, S Z. (1997), "A refined flexible inspection method for identifying surface flaws using the skeleton and neural network”, International Journal of Production Research, 35(9), pp. 2493-2507.

Wang, J. (1999), "Fuzzy outranking approach to prioritise design requirements in quality function deployment", International Journal of Production Research, 37(4), pp. 899-916.

Watson, I. and Marir, F. (1994), “Case-based Reasoning: a review”, The Knowledge Engineering Review, 9(4), pp. $1-39$

Webster, S. Jog D and Gupta A. (1998), “A genetic algorithm for scheduling job families on a single machine with arbitrary earliness/tardiness penalties and an unrestricted common due date", International Journal of Production Research, 36(9), pp. 2543-2551

Wei, L. (1999), “An extended Kalman filter and neural network cascade fault diagnosis strategy for the glutamic acid fermentation process", Artificial Intelligence in Engineering, 13(2), pp.131-140 
Wen, F. and Chang, C.S. (1999), "A new method for diagnostic problem solving based on a fuzzy abductive inference model and the tabu search approach", Artificial Intelligence in Engineering, 13(1), pp. 83-90

Wiers, V.C.S., (1997), A review of the application of OR and AI scheduling techniques in practice, Omega, 25, pp. 145-153.

Wong, T.N. and Siu, S. L. (1995), “A knowledge-based approach to automated machining process selection and sequencing", International Journal of Production Research, 33(12), pp.3465-3484

Xia, Q.J. and Rao, M. (1999), "Dynamic case-based reasoning for process operation support systems", Engineering Applications of Artificial Intelligence, 12(3), pp.343-361.

Yongting, C (1996), "Fuzzy quality and analysis on fuzzy probability”, Fuzzy sets and Systems, 83(2), pp. $283-290$.

Young, P., Byrne, G. and Cotterell, M. (1997), "Manufacturing and the environment", International Journal of Advanced Manufacturing Technology,.13(7), pp.488-493.

Yu, L., Shih, H.M. and Sekiguchi, T. (1999), "Fuzzy Inference-based multiple criteria FMS scheduling", International Journal of Production Research, 37(10), pp. 2315-2333.

Zeid, I., Gupta, S.M. and Bardasz, T. (1997), “A case-based reasoning approach to planning for disassembly", Journal of Intelligent Manufacturing, 8(2), pp.97-106

Zhang, H.C. and Zhang, D. (1995), "Concurrent engineering: an overview from manufacturing and engineering perspectives”, Concurrent Engineering: Research and Applications, 3, pp. 221-237.

Zhang, H.C. and Huang S.H (1995), "Application of neural networks in manufacturing: a state of the art", International Journal of Production Research, 33(3), pp. 705-728.

Zhang X. Bode J. and Ren S. (1996), "Neural networks in quality function deployment", Computers and Industrial Engineering, 31, pp 669-673

Zhang, F. and Jardine, A.K.S. (1997), “A smart maintenance decision system”, Proceedings of the European Conference on Intelligent Management Systems Operations, pp.79-86.

Zhang, Y. and Chen H. (1999), "A knowledge-based dynamic job-scheduling in low-volume/high-variety manufacturing”, Artificial Intelligence in Engineering, 13(3), 241-249 